Article

\title{
Acid Ionic Liquids as a New Hardener in Urea-Glyoxal Adhesive Resins
}

\author{
Hamed Younesi-Kordkheili ${ }^{1, *}$ and Antonio Pizzi ${ }^{2}$ \\ 1 Department of Wood and Paper Sciences and Technology, Faculty of Natural Resources, Semnan University, \\ Semnan 35131-19111, Iran \\ 2 LERMAB-ENSTIB, University of Lorraine, Epinal 88000, France; antonio.pizzi@univ-lorraine.fr \\ * Corresponding: Hamed.Younesi@semnan.ac.ir; Tel.: +98-911-355-4324; Fax: +98-233-362-6299 \\ Academic Editor: Frank Wiesbrock
}

Received: 23 January 2016; Accepted: 17 February 2016; Published: 24 February 2016

\begin{abstract}
The effect of acidic ionic liquid (IL) as a new catalyst on the properties of wood-based panels bonded with urea-glyoxal (UG) resins was investigated. Different levels of $N$-methyl-2-pyrrolidone hydrogen sulfate ([HNMP] $\mathrm{HSO}_{4}(0,1,2,3 \mathrm{wt} \%)$ ) were added to prepared UG resin. The resin was then used for preparing laboratory particleboard panels. Then, the properties of the prepared panels were evaluated. The structure of the prepared UG resin was studied by ${ }^{13} \mathrm{C} N M R$, and thermal curing behavior of the resin before and after the addition of IL was measured by DSC. Additionally, the main oligomers formed in the UG reaction were identified by matrix-assisted laser desorption/ionization time-of-flight (MALDI TOF) mass spectroscopy. The results indicated that IL can be used as an efficient catalyst for UG resin. The physicochemical tests indicated that the addition of [HNMP] $\mathrm{HSO}_{4}$ from 0 to $3 \mathrm{wt} \%$ decreased the $\mathrm{pH}$ value of the glue-mix, and the $\mathrm{pH}$ decreased on curing to the same level as urea-formaldehyde resins. The gel accelerated with increasing catalyst content and with the decreasing of the $\mathrm{pH}$ in the UG resin. The panels prepared with IL had higher mechanical strength and dimensional stability compared to those made from UG resins containing $\mathrm{NH}_{4} \mathrm{Cl}$. Scanning electron microscope (SEM) micrographs showed that the panels prepared with ionic liquid presented low porous. DSC analysis showed that the addition of IL to the UG resin decrease the energy of activation of the curing reaction to render possible cross-linking. The MALDI TOF results indicated a preponderant linearity of the oligomers formed, implying a high energy of activation of curing for UG resins.
\end{abstract}

Keywords: acidic ionic liquid; urea-glyoxal resin; catalyst; MALDI TOF; ${ }^{13}$ C NMR; DSC

\section{Introduction}

With the introduction of a non-toxic aldehyde such as glyoxal as a substitute of formaldehyde, urea-glyoxal (UG) resins can be produced as green wood adhesives. Contrary to urea formaldehyde (UF) resins, UG resins are eco-friendly and present lower water absorption and thickness swelling [1,2]. Hence, UG as green adhesive seems to have good potential in wood-based panels manufacturing in the near future.

UG resins as other thermoset aminoplastic resins need an acid medium to polymerize and cross-link [1]. It is for this reason that, in the previous studies, ammonium chloride $\left(\mathrm{NH}_{4} \mathrm{Cl}\right)$ was used as the usual acid catalyst in the preparation of panels bonded with UG resins [1,2]. So far, several research works were carried out on the importance of the use of catalysts in aminoplastic thermoset resins [3,4]. Among several types of catalysts, ammonium salts (such as $\mathrm{NH}_{4} \mathrm{Cl}$ and $\mathrm{NH}_{3} \mathrm{SO}_{4}$ ) are one of the most important and effective types of catalysts used for accelerating resin curing. Compared to other types of catalysts, $\mathrm{NH}_{4} \mathrm{Cl}$ is cheap, effective, free of annoying byproducts, and easy to use. The 
influence of $\mathrm{NH}_{4} \mathrm{Cl}$ on resin curing involves the release of hydrochloric acid $(\mathrm{HCl})$, which brings the $\mathrm{pH}$ to very low values and speeds up the resin cure rate. In spite of the several advantages of $\mathrm{NH}_{4} \mathrm{Cl}$ as a thermoset resin catalyst, it also presents some disadvantages: (I) several bubbles form in the glue line due to the decomposition of $\mathrm{NH}_{4} \mathrm{Cl}$ in the hot press and consequent emission of ammonia gas, which reduces the mechanical strength of the resin and of the panels bonded with it; (II) furthermore, chlorine $(\mathrm{Cl})$ is a toxic element and raises concerns of environmental pollution, especially in the case of green adhesives such as UG resins; (III) the residual acid left in the glue line as a consequence of the addition of an acid catalyst can increase the degradation of the cured resin in particleboards [3] as well as causing degradation by acid hydrolysis of the wood carbohydrates at the interface wood/adhesive. Thus, due to the defects of $\mathrm{NH}_{4} \mathrm{Cl}$, and the green nature and low mechanical strength of the UG resins, it is imperative to find a nontoxic and eco-friendly high-quality catalyst.

Conversely, ionic liquids (ILs), which have been widely promoted as "green solvents," are attracting much attention for applications in many fields of chemistry and industry due to their chemical stability, thermal stability, low vapor pressure and high ionic conductivity properties [5]. Over the last few years, ILs have been popularly used as solvents for organic synthesis and also have been used as media for extraction processes [5]. Previous studies have indicated that ILs can also be used as an efficient catalyst in the synthesis of various materials. Among different types of ionic liquids used as catalysts, Brønsted acidic ionic liquids such as $N$-methyl-2-pyrrolidone hydrogen sulfate ([NMP]+$+\mathrm{HSO}_{4}^{-}$) has been reported as being most effective in terms of short reaction time and with excellent yields of the desired product [6]. Wang et al. (2011) indicated that ([NMP]+HSO $\left.{ }_{4}^{-}\right)$can be used as a substitute of various types of homogenous and heterogeneous catalysts due to its special properties such as being green, of low viscosity, non-volatile, recyclable and inducing no corrosion [7]. Additionally, Brønsted acidic ionic liquids are emerging as most promising alternatives for a wide variety of acid-catalyzed reactions, as they have useful characteristics of both solid acids and mineral liquid acids, and they can be designed to replace customary mineral liquid acids such as sulfuric acid and hydrochloric acid in chemical processes [6].

Regarding the type and the content of the catalyst directly affecting resin curing and the performances of final products [3], the aim of this study was the investigation of the effect of Brønsted acidic ionic liquids as a new resin catalyst on the physical and mechanical properties of the wood-based panels bonded with UG resins. It is important to note that the acid part of the IL obtained by its hydrolysis due to the increased temperature during hot pressing is the accelerator of resin hardening. The added advantage is that, as the hardened glue line cools, since none of the two parts of the IL are volatile, the almost neutral IL forms again, bringing the $\mathrm{pH}$ of the hardened adhesive to almost neutral again. The period of acid contact with the wood surface is very short, thus minimizing any hydrolysis damage to the wood surface carbohydrates [8]. The resultant strength of the panel is then unaffected.

\section{Materials and Methods}

\subsection{Preparation of UG Resin}

The UG resin was prepared according to the method of Deng et al. (2014) [1]. Glyoxal (40\%) was placed in the reactor, and the reaction $\mathrm{pH}$ was adjusted to $4-5$ with a $30 \% \mathrm{NaOH}$ solution. Subsequently, the first urea (U1) was added, and the mixture was then heated to $75^{\circ} \mathrm{C}$ for $2 \mathrm{~h}$. Then, the second urea (U2) was added, and the reaction mixture became a weak acid at $\mathrm{pH} 4-5$ for $1 \mathrm{~h}$ at $75^{\circ} \mathrm{C}$. Lastly, the reaction mixture became a weak alkaline at $\mathrm{pH} 7.5$ and cooled to room temperature ready for use. The $\mathrm{U} 1 / \mathrm{U} 2$ weight ratio was 2:1. UG resins used for this study were prepared at G/U molar ratio of 1.4:1.

\section{2. $[\mathrm{HNMP}]\left[\mathrm{HSO}_{4}\right]$ Synthesis}

[HNMP] $\mathrm{HSO}_{4}$ was synthesized according to the method of Wang et al. 2011 [7]. $1.0 \mathrm{~mol} \mathrm{~N}$-methyl pyrrolidone was weighed and placed into a $250 \mathrm{~mL}$ three-neck flask, and $1.0 \mathrm{~mol}$ sulfuric acid was added dropwise into the $250 \mathrm{~mL}$ three-neck flask with a dropping funnel under continuous mechanical 
stirring by magnetic stirrer at room temperature. A considerable amount of white smoke appeared during the dropwise addition of acid. The mixture became a sticky, light yellow transparent liquid after stirring at $80^{\circ} \mathrm{C}$ for $4 \mathrm{~h}$. The resultant liquid [HNMP] $\mathrm{HSO}_{4}$ was washed three times with ether and ethyl acetate, respectively, and was dried under vacuum to remove the ether and ethyl acetate. The schematic synthesis of [HNMP] $\mathrm{HSO}_{4}$ is shown in Figure 1.

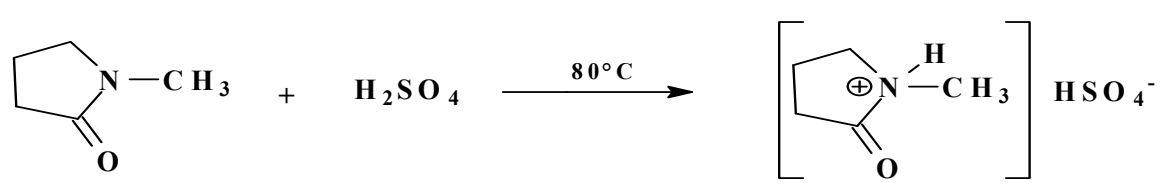

Figure 1. Synthesis of [HNMP] $\mathrm{HSO}_{4}$.

\subsection{Addition of Catalysts to UG Resin}

Different proportions of [HNMP] $\mathrm{HSO}_{4}(0,1,2,3 \mathrm{wt} \%)$ were added to prepare the UG resin at room temperature. To compare the performance of the acidic ionic liquid with $\mathrm{NH}_{4} \mathrm{Cl}$, a UG resin containing $2 \mathrm{wt} \% \mathrm{NH}_{4} \mathrm{Cl}$ (20\% solution) was prepared as a control sample. These resins were then immediately used to prepare the wood panels.

\subsection{Measurements of the $\mathrm{pH}$ and Gel Time}

The $\mathrm{pH}$ values of the resins at both ambient and elevated temperatures were measured with a Hanna $\mathrm{pH}$ meter (Limena, Italy). Before each measurement, the $\mathrm{pH}$ meter was calibrated with standardized buffer solutions at $\mathrm{pHs}$ of 4 and 7. After calibration, $200 \mathrm{~g}$ of a UG sample was pipetted into a $250-\mathrm{mL}$ beaker, and the initial $\mathrm{pH}$ values of the resin and the solution, adjusted by the gradual addition of [HNMP] $\mathrm{HSO}_{4}$ from $0 \%$ to $3 \%$ (solids on solids), were recorded as ambient $\mathrm{pH}$ after $5 \mathrm{~min}$ of magnetic stirring at $20^{\circ} \mathrm{C}$. For measuring $\mathrm{pH}$ at hot condition, the temperature of UG resin increased to about $50{ }^{\circ} \mathrm{C}$ (before gelation state occurred), and ILs were then added to the resin. $\mathrm{pH}$ value was measured at this temperature as hot $\mathrm{pH}$. In order to determine the gel time, five grams of the resin were introduced into a dry glass beaker. Then, aqueous acidic ionic liquid was added to the resin. The beaker was then immersed in boiling water, and the time until hardening was measured according to the Younesi-Kordkheili et al. (2015) method [9]. Two replicates for each sample were made.

\subsection{DSC Analysis}

The changes in enthalpy and curing temperature of the resins were determined using the thermal analyzer NETZSCH DSC $200 \mathrm{~F} 3$ model. The DSC scans were recorded at a heating rate of $10^{\circ} \mathrm{C} / \mathrm{min}$ under nitrogen atmosphere with a flow rate of $60 \mathrm{~cm}^{3} / \mathrm{min}$. To determine the curing temperature of the resins, about $5 \mathrm{mg}$ of freeze-dried sample was added to the aluminum pan. Additionally, 2\% ILs was added to the prepared resins (based on dry weight) before measuring the curing temperature of resins. Then, the samples were heated from ambient temperature $\left(25^{\circ} \mathrm{C}\right)$ to $200^{\circ} \mathrm{C}$ under nitrogen atmosphere.

\subsection{CP-MAS ${ }^{13} C$ NMR Analysis}

Solid-state cross-polarization/magic angle spinning ${ }^{13} \mathrm{C}$ nuclear magnetic resonance (CP-MAS ${ }^{13} \mathrm{C}$ NMR spectrum of the hardened resin after grinding to a very fine powder was recorded on a Brüker MSL 300 spectrometer at a frequency of $75.47 \mathrm{MHz}$. Chemical shifts were assigned relative to tetramethyl silane (TMS). The rotor was spun at $4 \mathrm{kHz}$ on a double bearing 7-mm Brüker probe. The spectrum was acquired with $5 \mathrm{~s}$ recycle delay, a $90^{\circ}$ pulse of $5 \mu \mathrm{s}$, and a contact time of $1 \mathrm{~ms}$, and the number of transients was 3000 . 


\subsection{MALDI TOF-MS Analysis}

The samples were dissolved in acetone $(5 \mathrm{mg} / \mathrm{mL})$. 2,5-dihydroxy benzoic acid was used as the matrix. For the enhancement of ion formation, $0.1 \mathrm{M} \mathrm{NaCl}$ was added to the matrix. The solutions of the sample and matrix were mixed in equal amounts, and $1.5 \mu \mathrm{L}$ of the resulting solution was placed on the MALDI target. After evaporation of the solvent, the MALDI target was introduced into the spectrometer. The spectra were recorded on a MALDI TOF instrument (AXIMA Performance, Shimadzu, Manchester, UK). The irradiation source was a pulsed nitrogen laser with a wavelength of $337 \mathrm{~nm}$. The duration of a single laser pulse was $3 \mathrm{~ns}$. The measurements were carried out using the following conditions: polarity-positive, flight path-linear, mass-high ( $20 \mathrm{kV}$ acceleration voltage), and $100-150$ pulses per spectrum. The delayed extraction technique was used by applying delay times of 200-800 ns.

\subsection{Particleboard Manufacturing}

The manufacturing of the particleboards was performed according to the method of Younesi-Kordkheili et al. (2015) [10]. A forming mold frame $(35 \mathrm{~cm} \times 35 \mathrm{~cm} \times 1 \mathrm{~cm})$ was placed on a stainless steel caul plate to control thickness. The surfaces of each plate were sprayed with a mineral oil releasing agent to ease demolding of the panel after hot pressing. Dried particles were then blended with the prepared resins in a rotating drum-type mixer fitted with a pneumatic spray gun. Then, compounded material was poured into the frame and spread to fill the frame evenly. When forming was complete, the top caul plate was placed on the top of the mat, and the entire assembly was placed into an oil-heated press that was used for compression molding. The temperature of the press plates was maintained at $180{ }^{\circ} \mathrm{C}$ at a maximum pressure of 25 bar pressure. The pressing of the compound material was carried out respectively in two stages by hot and cold presses for $5 \mathrm{~min}$. A $5 \mathrm{~cm}$ wide edge of each board was trimmed to remove the low density and poor bonding areas of the boards [11]. To ensure reproducibility, three panels were manufactured for each formulation. The nominal thickness and density of manufactured panels was $16 \mathrm{~mm}$ and $0.8 \mathrm{~g} / \mathrm{cm}^{3}$, respectively. Preparation of the samples for mechanical tests and water absorption measurements was started $24 \mathrm{~h}$ after pressing.

\subsection{Panel Testing}

All physical and mechanical tests of the particleboards prepared were carried out to the appropriate standard methods. The tests performed on the specimens were internal bond strength (IB-tensile strength perpendicular to the panel plane) [12], static bending [bending strength and modulus of elasticity (MOE)] [13] and water absorption and thickness swelling [14]. The samples were conditioned at a temperature of $23 \pm 2{ }^{\circ} \mathrm{C}$ and a relative humidity of $60 \% \pm 5 \%$ for two weeks. Five specimens were tested for each panel.

\subsection{Scanning Electron Microscopy (SEM)}

The morphology of the particleboards was examined using a scanning electron microscope (XL30) supplied by Semtech Limited (Neuchatel, Switzerland). The fracture surfaces of the specimens after the bending test were sputter-coated with gold before analysis. All images were taken at an accelerating voltage of $17 \mathrm{kV}$.

\section{Results and Discussion}

\subsection{Effect of the [HNMP] $\mathrm{HSO}_{4}$ Content on the $\mathrm{pH}$ and Gel Time of the UG Resin}

The $\mathrm{pH}$ value of the UG resin decreased with increasing [HNMP] $\mathrm{HSO}_{4}$ content from $0 \%$ to $3 \%$, as shown in Figure 2. Figure 2a showed that decrease in the $\mathrm{pH}$ value was initially very quick, and the slope of curve then became less sharp with increasing catalyst content. The effect of [HNMP] $\mathrm{HSO}_{4}$ on 
UG-resin curing is to release $\mathrm{H}^{+}$and $\mathrm{HSO}_{4}{ }^{2-}$. With an increasing $\mathrm{HSO}_{4}{ }^{2-}$ concentration in the system, the rate of $\mathrm{HSO}_{4}{ }^{2-}$ release is retarded. Thus, the $\mathrm{pH}$ decreases very quickly in the beginning and then more slowly (Figure 2a).

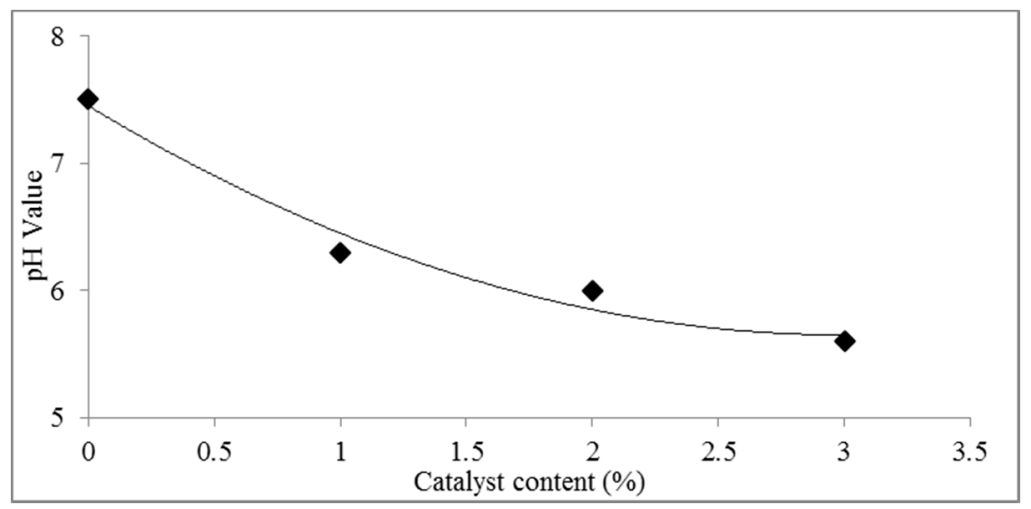

(a)

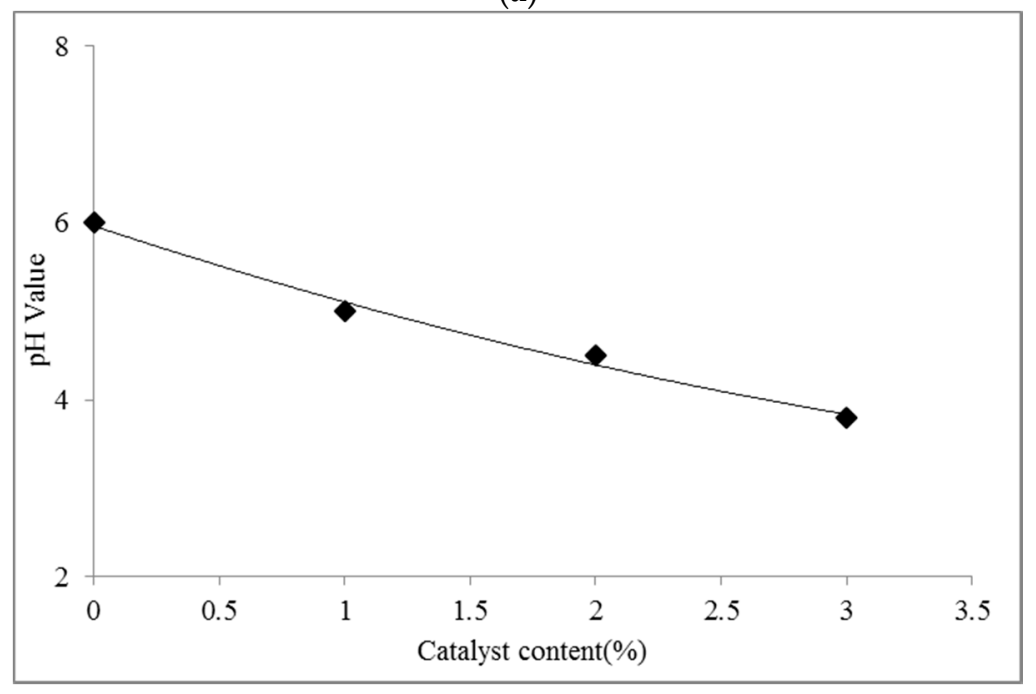

(b)

Figure 2. $\mathrm{pH}$ value of the UG resin versus the acidic ionic catalyst content at (a) ambient temperature (b) hot temperature.

According to Figure 2a, the curve of the UG resin containing $0 \%, 1 \%, 2 \%$ and $3 \%$ catalyst shows remarkable differences in $\mathrm{pH}$ values. This seems to contradict the previous findings about the influence of $\mathrm{NH}_{4} \mathrm{Cl}$ on UF resins. Previous studies have indicated that the $\mathrm{pH}$ value of UF resin decreases with catalyst addition very quickly at the beginning, but the changes in the $\mathrm{pH}$ value become smaller with increases in the catalyst content [4]. This finding indicates that, compared to $\mathrm{NH}_{4} \mathrm{Cl}$, the use of acidic ionic liquid as a catalyst can decrease the $\mathrm{pH}$ value uniformly and continuously. Additionally, Figure $2 \mathrm{~b}$ indicated that increasing ILs from $0 \%$ to $3 \%$ decreased the $\mathrm{pH}$ of resin at a hot temperature. This finding gives important information about the behavior of UG resin under a hot pressing condition for wood panel manufacturing. According to Figure $2 \mathrm{~b}$, the $\mathrm{pH}$ of the resin is still higher than 3.8, even with the addition of $3 \%$ catalyst. This is comparable to the $\mathrm{pH}$ obtained by catalyzed urea-formaldehyde resins, and it ensures that the $\mathrm{pH}$ reached on curing by the UG resin catalyzed with IL is not damaging to the lignocellulose of the wood substrate.

One of the most important resin parameters affecting the processing of wood-based panels is the resin gel time. The gel time is the time from when the material begins to soften to when gelation occurs, where gelation is the irreversible transformation from a viscous liquid to an elastic gel. The effect of 
the acidic ionic liquid content on gel time is shown in Figure 3. It can be seen that the addition of ILs from $1 \%$ to $3 \%$ significantly reduces the gel time of UG resins. The faster gel time of catalyzed UG resins indicates that their cross-linking rate becomes faster by adding [HNMP] $\mathrm{HSO}_{4}$. The shortening of the resin gel time with the addition of the catalyst is surely related to the decreasing $\mathrm{pH}$ value. The advantages of shorter gel times of thermoset resins with the addition of catalysts have been reported by several researchers [15-17].

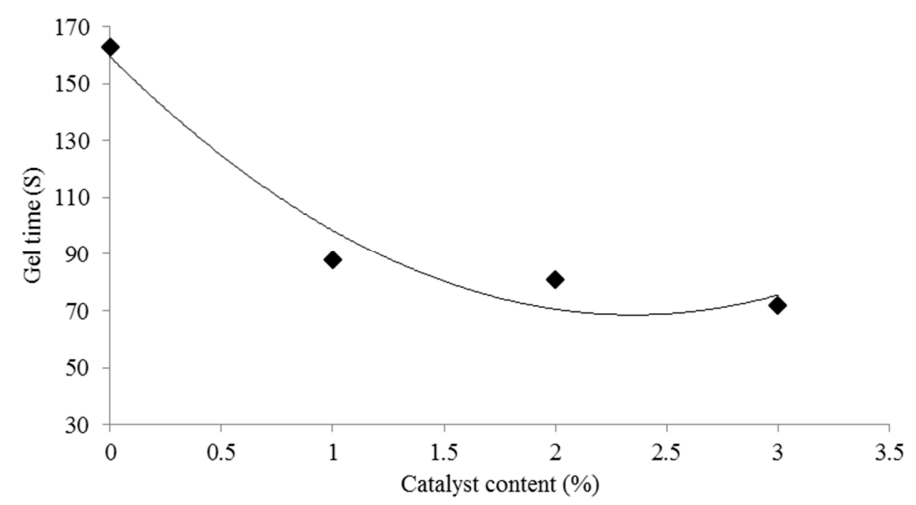

Figure 3. Effect of acidic ionic catalyst content on gel time of UG resin.

\subsection{DSC Results}

The influence of ILs on thermal curing behavior of UG resins was investigated by DSC. The DSC curves of the UG resin without catalyst and UG resin with $2 \%$ ILs are shown in Figure 4 . The curing of the UG resin is an exothermic reaction similar to other formaldehyde-based thermoset resins. The exothermic peak of the UG resin is affected by the presence of the ionic liquid. Adding the IL caused the peak of temperature $\left(T_{\text {peak }}\right)$ to be reached much earlier and at a lower peak temperature. For the pure UG resin, the average $T_{\text {peak }}$ was about $103^{\circ} \mathrm{C}$. Adding the ILs did change the peak temperature to $77^{\circ} \mathrm{C}$. The decrease in peak temperature of the UG resin containing the IL catalyst indicated that ILs accelerates the hardening of a UG resin. The DSC analysis also showed that $T_{\text {onset }}$ increased from 35 to $45{ }^{\circ} \mathrm{C}$ with the addition of $2 \%$ ionic liquid. The clear indications of all these are the addition of IL to the UG resin decreasing the energy of activation of the curing reaction, rendering possible cross-linking. This was confirmed by the DSC results showing that the enthalpy of the cure reaction $(\Delta H)$ (the area under the DSC exotherm curves) of the UG resin containing ILs was lower than that of pure UG, indicating also that low heat was generated by this mix.

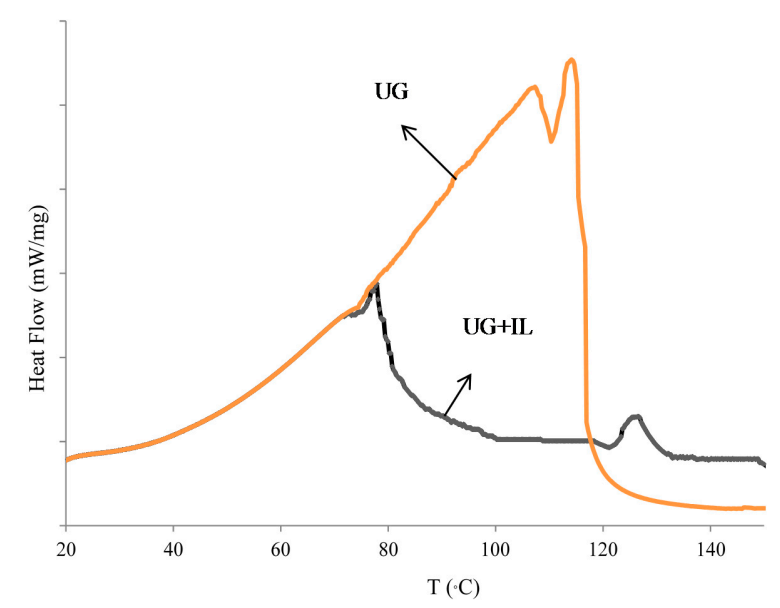

Figure 4. DSC curve of the UG resin and UG resin $+2 \%$ ILs. 


\section{3. ${ }^{13} \mathrm{C}$ NMR of UG Resin}

Previous studies have reported that the structure and property of thermoset resins vary as the synthesis conditions change [2]. Nuclear magnetic resonance spectroscopy (NMR) is one of the most effective methods of studying resin structure. So far, ${ }^{13} \mathrm{C}$ NMR has been used to characterize the structures of various resins, such as UF, PF and PUF resins. The solid phase CP MAS ${ }^{13} \mathrm{CNMR}$ spectra of a hardened UG resin is shown in Figure 5. The NMR of the hardened UG resin shows some features of interest. The shift at $163 \mathrm{ppm}$ is indicative of the $\mathrm{C}=\mathrm{O}$ of urea disubstituted for reaction with the glyoxal, and the shift at $154 \mathrm{ppm}$ indicates a urea more multisubstituted, indicating tridimensional cross-linking of the hardened resin. The shifts at 87,77 and $61 \mathrm{ppm}$ are indicative of the carbon shifts of the following repeating unit,

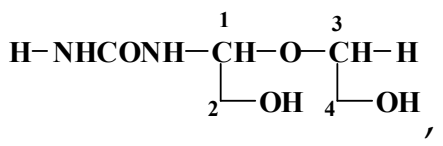

with the $87 \mathrm{ppm}$ shift belonging to the $\mathrm{C} 1$ carbon directly linked to the -NH-group of urea, the $77 \mathrm{ppm}$ shifts to the $\mathrm{C} 3$ not linked to the urea, and the wide but small 61-62 ppm peak belonging to the $\mathrm{C} 2$ and $\mathrm{C} 4$ of the repeating unit above.

The peak at 100 ppm belongs to the $C$ linked to two urea molecules, as in the structure:
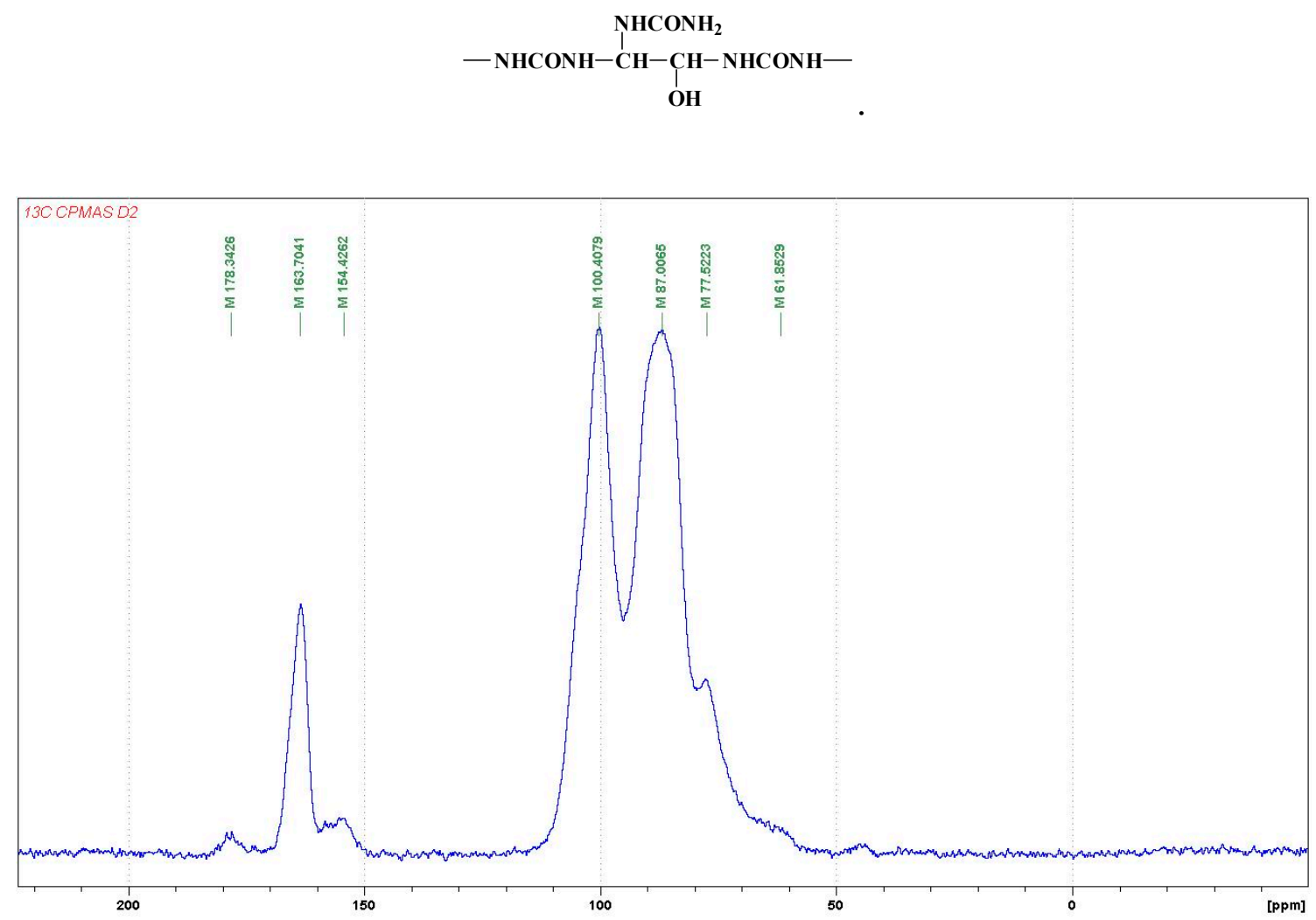

Figure $5 .{ }^{13} \mathrm{C}$ NMR spectrum of UG resin.

\subsection{MALDI TOF Results}

The MALDI TOF spectrum in Figure 6 shows a number of peaks. There are clearly two repeating motives in the spectrum, one of $175+1 \mathrm{Da}$ and a second one of $161+1 \mathrm{Da}$. 


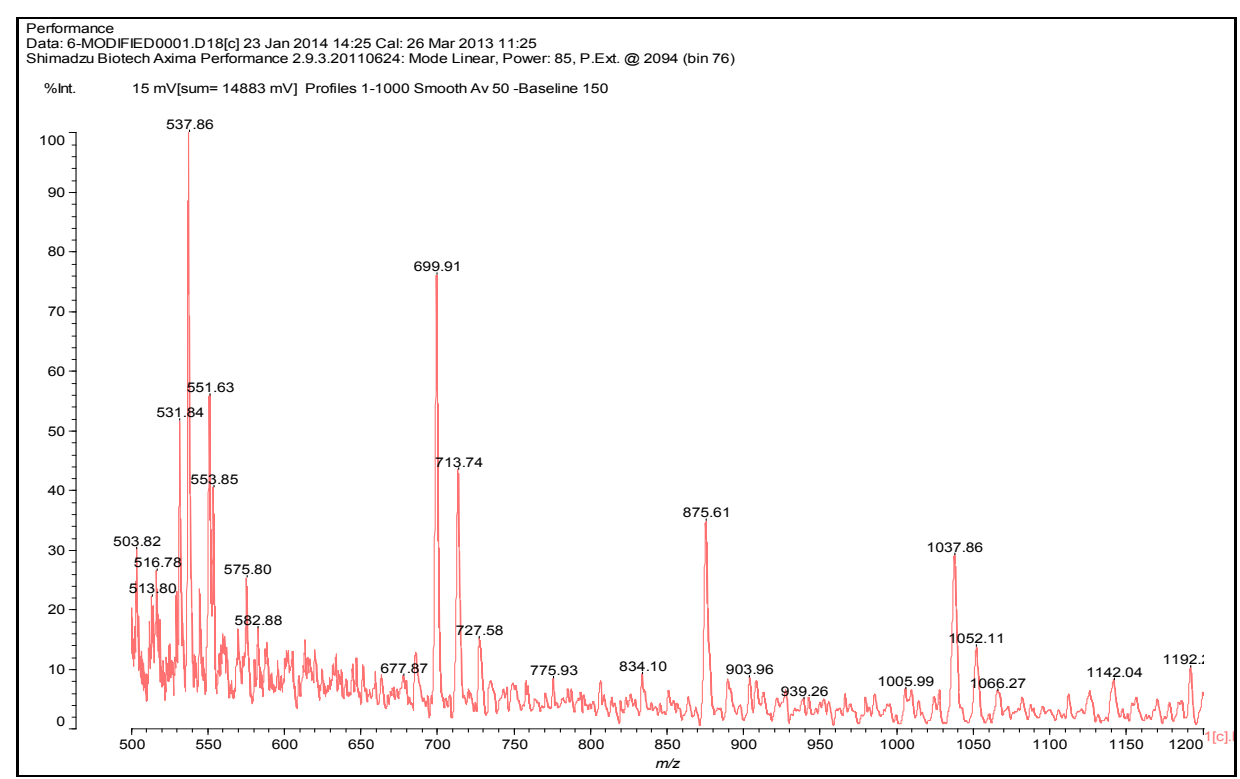

Figure 6. MALDI TOF spectrum of the UG resin.

These are representative of the following two repeating units, namely for the 174-176 Da:

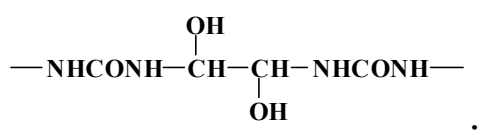

The second repeating mass interval at $162 \mathrm{Da}$ is indicative of the following repeating unit:

$$
-\mathrm{NHCONH}^{-\mathrm{CH}-\mathrm{O}-\mathrm{CH}-}
$$

The two units are forced to alternate to form a repeating unit that is:

$$
\begin{aligned}
& \mathrm{OH}
\end{aligned}
$$

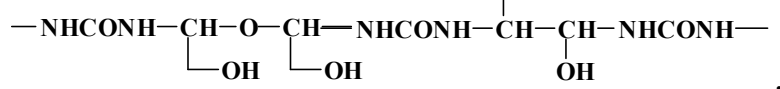

This alternance give rise to the series of peaks at 699-728, 875, 1037 and 1192 Da.

The following one in the series is:

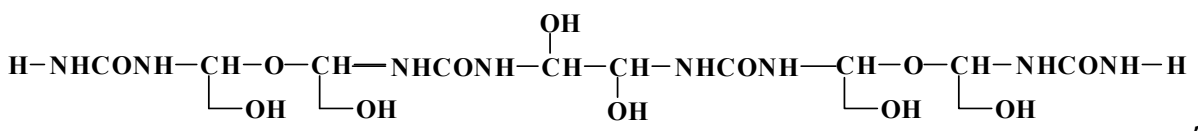

and so on. The peak at $538 \mathrm{Da}$ is derived from the above oligomer species by the loss of a $-\mathrm{CH}_{2} \mathrm{OH}$ group and added to the $\mathrm{Na}+$ used as a matrix enhancer. Thus, for example, the peak at $728 \mathrm{Da}$ is the following molecule deprotonated and added to $23 \mathrm{Da}$ of the $\mathrm{Na}^{+}$used as enhancer of the matrix

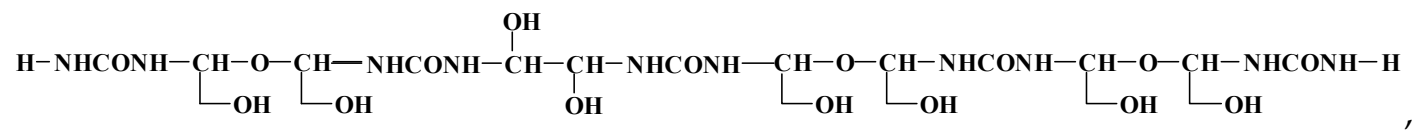

$728 \mathrm{Da}$, deprotonated $+\mathrm{Na}^{+}$. 
The peaks at respectively 699 and $713 \mathrm{Da}$ are obtained from the above molecule by the loss of an $-\mathrm{CH}_{2} \mathrm{OH}$ and $-\mathrm{OH}$ group, respectively. The peak at $875 \mathrm{Da}$ is derived from the addition of a 176 motive to the 713 peak to form an oligomer of the type

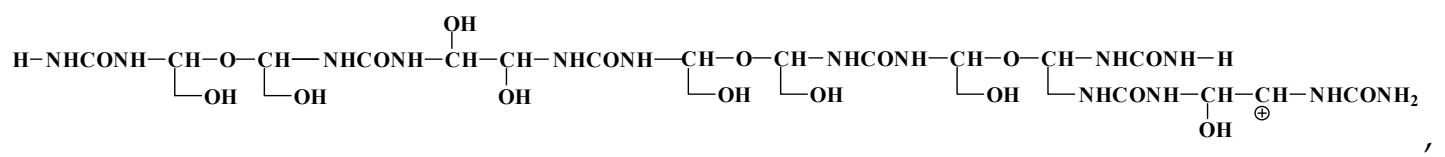

which, added to the $\mathrm{Na}^{+}$used as a matrix enhancer, gives $875 \mathrm{Da}$. The following peak at 1037-1038 $\mathrm{Da}$ is the oligomer derived by adding a further $162 \mathrm{Da}$ fragment to the $875 \mathrm{Da}$ oligomer, giving the following type of oligomer:

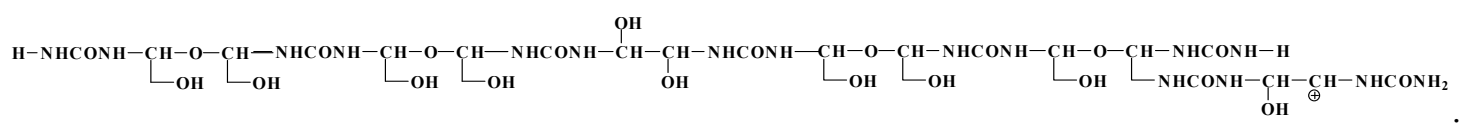

Three more findings result from the MALDI TOF analysis, the first of which being that the $-\mathrm{CH}-\mathrm{O}-\mathrm{CH}-$ ether bridges are formed by glyoxal resins just as easily as methylene ether bridges are formed in UF resins. These types of bridges, however, appear to be more stable than the methylene ether bridges of UF resins, where rearrangements with elimination of formaldehyde are rather common. However, rearrangements of such bridges with elimination of glyoxal cannot be excluded at this stage. These glyoxal ether bridges present in the 162-Da repeating unit alternate with definite - $\mathrm{CH}-\mathrm{CH}-$ bridges characteristics of the 176-Da repeating unit. One last thing evident from the MALDI analysis is that the oligomers formed are mainly linear and appear to present little ramification, a fact that should definitely have a bearing on the gelling and curing time and behaviors of such adhesives. One of the bearings of these characteristics is most likely to be the higher energy activation for curing UG resins than that for UF resins. That is why ILs, and the lower pHs reached during hot-pressing, are necessary for proper curing.

As regards to the lower $\mathrm{pH}$ reached on curing, this has been shown to do little damage to the lignocellulosic substrate due to a very short period of time the acid is free and in contact with it, exclusively during the short hot pressing time, before being again neutralized on the cooling of the panel and the reforming of the IL in the cured resin [8]. Moreover, the $\mathrm{pHs}$ reached with the adhesive system UG+IL are not lower than what was achieved by a UF resin and a standard hardener.

\subsection{Properties of Particleboards}

Water absorption and thickness swelling of wood-based panels is one of the main factors that limit their outdoors application. As regards to this issue, several researchers have focused on finding new methods to reduce water absorption of wood-based panels $[9,18]$. Short-term water absorption and thickness swelling of the panels prepared are shown in Figures 7 and 8 respectively.

These figures (Figures 7 and 8) show that water absorption and thickness swelling increase with increasing immersion time. The panels prepared without any catalysts exhibit the highest water absorption (23\%) and thickness swelling (16\%). Conversely, the panels containing acidic ionic liquid exhibit lower water absorption and thickness swelling compared to those catalyzed with $\mathrm{NH}_{4} \mathrm{Cl}$. The results also show that the lower water absorption and thickness swelling content can be achieved by increasing the ionic liquid proportion from $0 \%$ to $3 \%$, as shown by the panels containing $3 \%$ [HNMP] $\mathrm{HSO}_{4}$ exhibiting lower water absorption and thickness swelling. Higher water absorption and thickness swelling of the panels prepared with $\mathrm{NH}_{4} \mathrm{Cl}$ compared to those containing [HNMP] $\mathrm{HSO}_{4}$ can be explained by the SEM micrographs. SEM micrographs shown later indicate that, contrary to $\mathrm{NH}_{4} \mathrm{Cl}$, the fracture surface of the panels prepared with the ionic liquid, produces no porosity and voids in glue line. These voids are the place where water molecules accumulate and increase the panel's water absorption and thickness swelling. Conversely, it appears that the glue lines will be 
smoother and therefore less capable of absorbing water molecules in this region by increasing the acidic ionic liquid content. Kardos et al. (1986) also indicated that some microcracks and voids are created during the UF resins curing process [19].

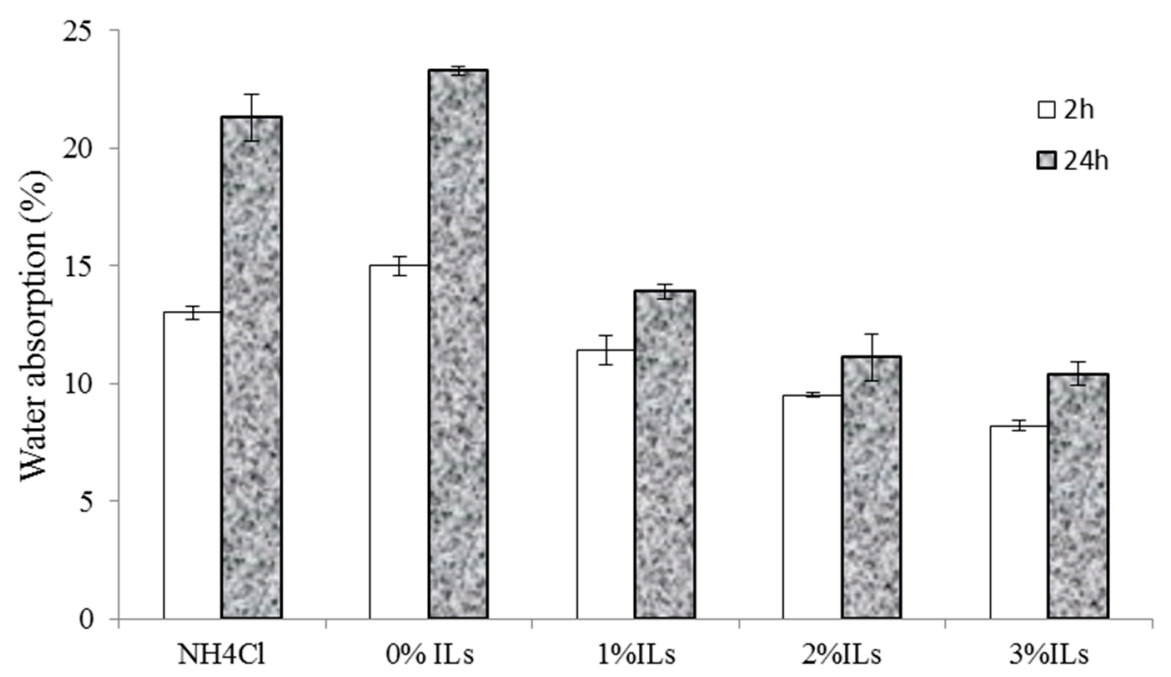

Figure 7. Water absorption of the manufactured panels made from synthesized resins.

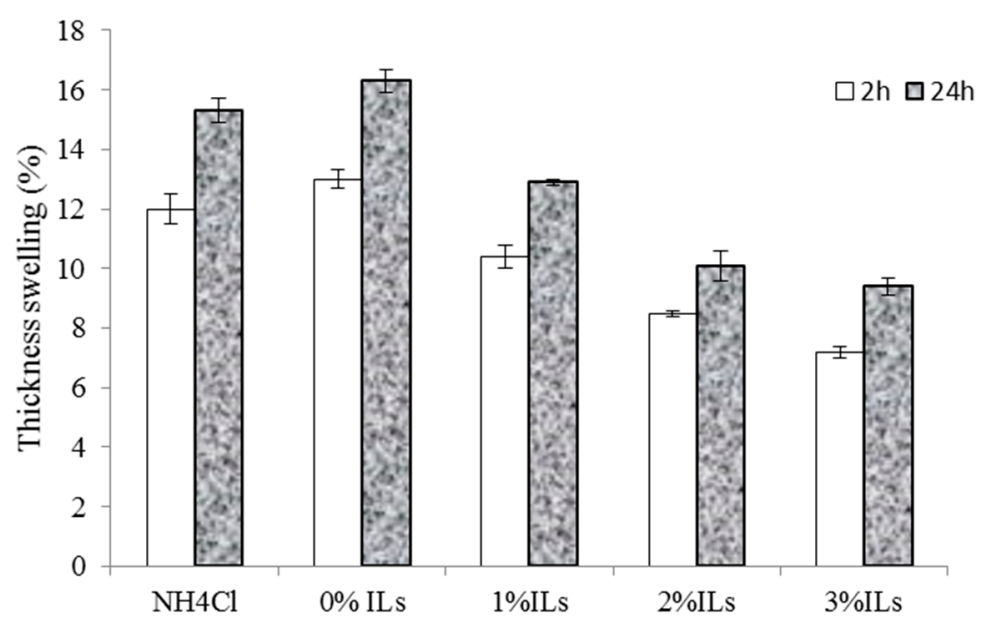

Figure 8. Thickness swelling of the manufactured panels made from synthesized resins.

The flexural modulus and strength of the panels containing $0 \%, 1 \%, 2 \%$ and $3 \%$ acidic ionic liquid compared to those had $\mathrm{NH}_{4} \mathrm{Cl}$ are illustrated in Figures 9 and 10 respectively. It can be observed that panels with acidic ionic liquid exhibited higher flexural modulus and strength values than those that used ammonium chloride as a catalyst.

As shown in Figures 9 and 10 increasing acidic ionic liquid content from $0 \%$ to 3\% into UG resin improved flexural properties of the panels. The highest flexural modulus and strength values were related to UG resin contain 3\% [HNMP] $\mathrm{HSO}_{4}$ as a catalyst, whereas the UG resin without catalysts exhibited the lowest values. In spite of the fact that glue line can act as a stress concentration point in bending strength, the higher MOE and MOR of the panels made from UG resin with acidic ionic liquid can be attributed to increasing mechanical properties of the resins with the addition of acidic ionic liquid. In addition, in hot press condition, the voids were produced after resin shrinkages or evaporation HCL gas in the UG resin structures. The voids in the glue line can reduce the mechanical properties of the resin as well as the panels. So far, several researchers have shown that a high amount of addition of $\mathrm{NH}_{4} \mathrm{Cl}$ decreases the mechanical strength of the resin and associated panels [20]. 


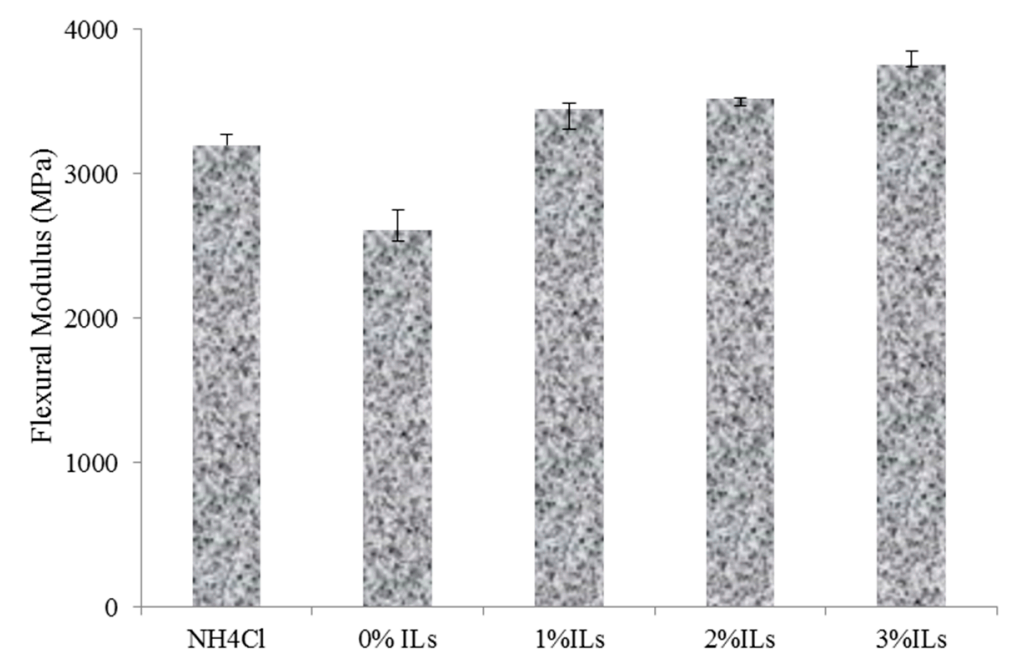

Figure 9. Flexural modulus of the manufactured panels made from synthesized resins.

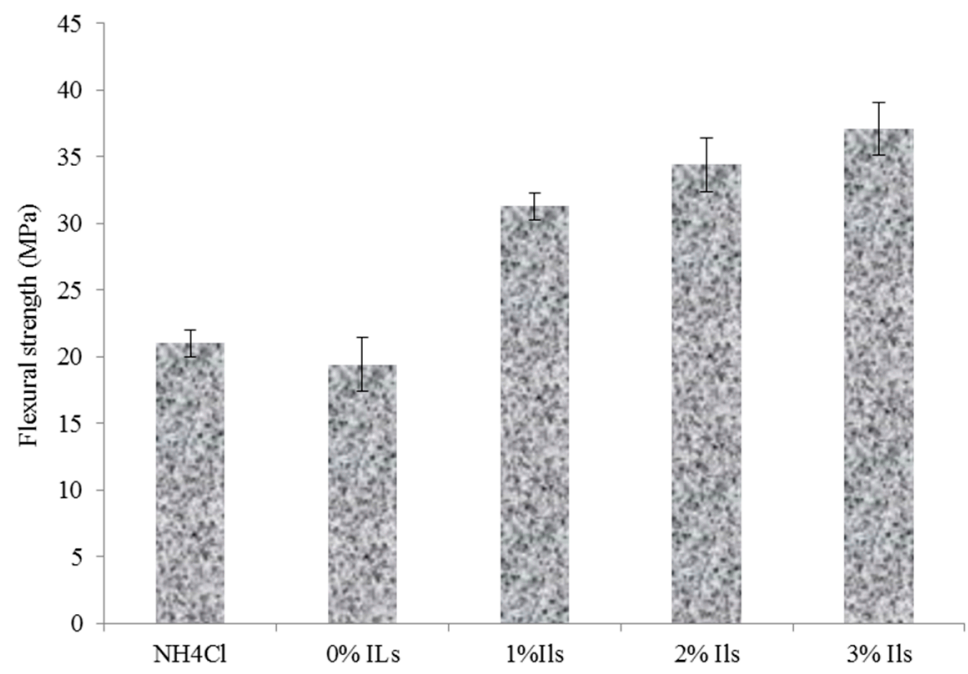

Figure 10. Flexural Strength of the manufactured panels made from synthesized resins.

Internal bond (IB) of the manufactured panels is shown in Figure 11. It can be seen that greater IB value can be achieved for the panels made from UG resin with the addition of catalysts. The panels made with $1 \%, 2 \%$ and $3 \%$ ionic liquid had $27 \%, 62 \%$ and $130 \%$ higher IB strength than the control samples $\left(\mathrm{NH}_{4} \mathrm{Cl}\right)$, respectively. The greater IB strength can be attributed to higher heat conductivity of the ionic liquid compared to wood particles and $\mathrm{NH}_{4} \mathrm{Cl}$. This causes better polymerization of the resin in the board core layer. So far, several researchers have indicated that the use of materials with higher heat transfer properties can reduce the hot press time and increase IB strength of the panel [21]. Wang et al. (2014) investigated the influence of various types of catalysts on the synthesis of different materials [7]. They indicated that [NMP] $+\mathrm{HSO}_{4}$ exhibited the best catalyst results among various acidic ionic liquids because it has several advantages: (1) the IL [NMP]+HSO 4 shows better catalytic activity and high yields; (2) the halogen free IL is more advantageous and the solvent free conditions for its use meet the greener aspects of catalysis; and (3) [NMP] $+\mathrm{HSO}_{4}$ can be easily recycled after separation.

\subsection{Morphology Characteristics}

Scanning electron microscopy is an effective media for the morphological investigations of wood-based panels. Figure 12a corresponds to the panels hardened with $\mathrm{NH}_{4} \mathrm{Cl}$. As can be seen, there 
are bubbles in the fracture surface that cause weakness sites in the panels. Therefore, when stress is applied, it causes fractures to occur faster in this region. Contrary to the panels contain $\mathrm{NH}_{4} \mathrm{Cl}$, there are no voids and bubbles in the particleboards with acidic ionic liquid hardeners (Figure 12b). Previous researchers have indicated that the existence of cavities in the wood-based panels helps the panels to absorb water and reduce mechanical properties. The panels, hardened with the green catalyst, present a smooth and monotonous matrix, and water penetration in the panels' deeper holes and cavities is thus prevented. Previous studies have also shown that the high strength of the glue line directly influences the panels' mechanical strength.

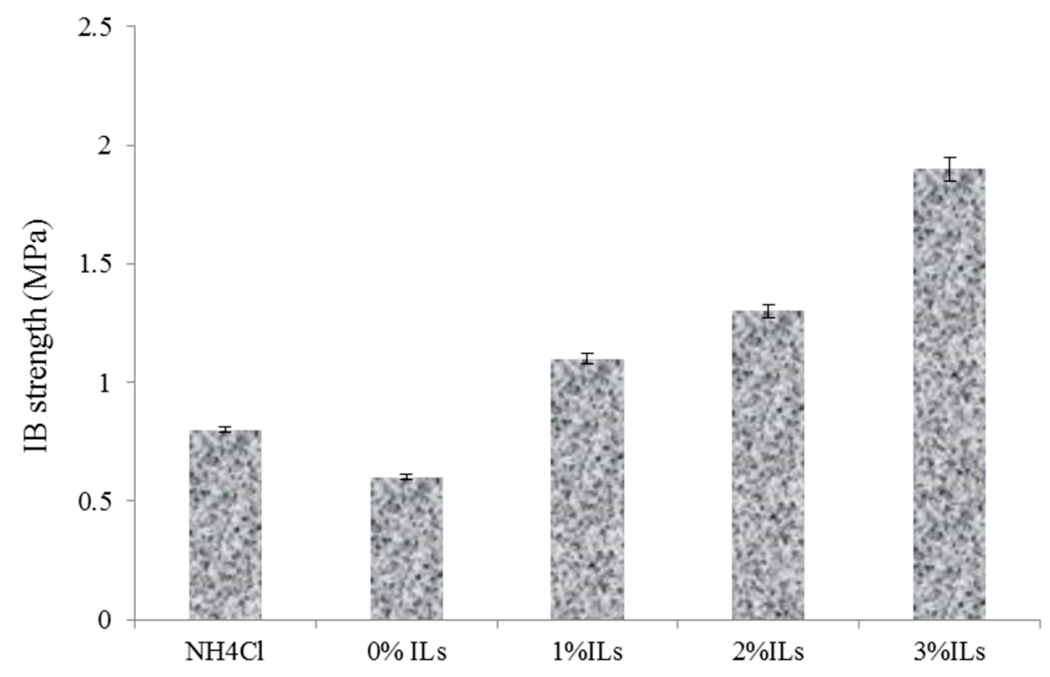

Figure 11. Internal bond strength (IB) of the manufactured particleboard made from synthesized resins.

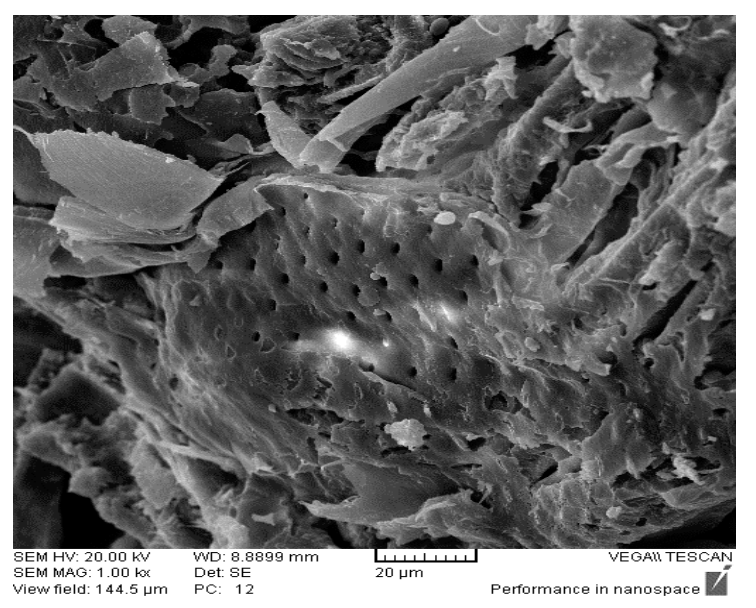

(a)

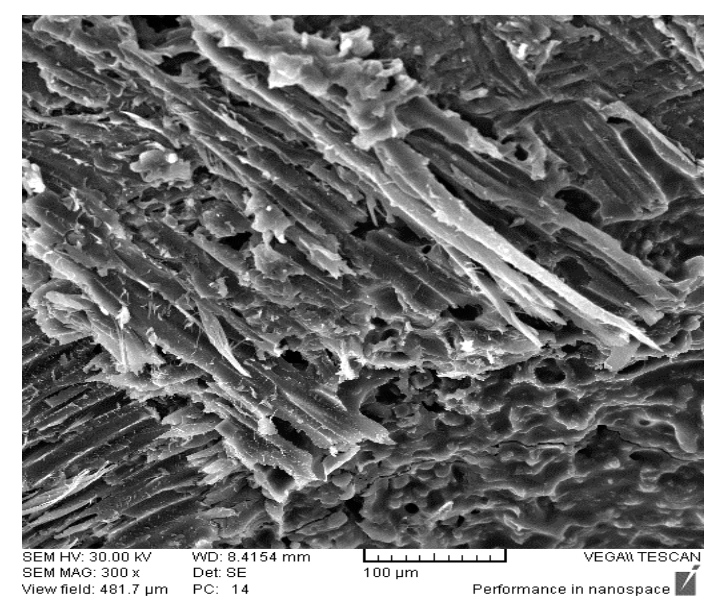

(b)

Figure 12. SEM micrograghs of the particleboards prepared with (a) UG resin $+\mathrm{NH}_{4} \mathrm{Cl}$; (b) UG resin+ ionic liquid.

\section{Conclusions}

In this work, the effect of an acidic ionic liquid ([HNMP] $\mathrm{HSO}_{4}$ ) as a new catalyst on physical and mechanical properties of wood-based panels bonded with urea-glyoxal (UG) resin was investigated. The following conclusions can be drawn from the results:

- Acidic ionic liquids, such as a halogen-free and ecofriendly ionic liquid, is an effective catalyst for urea-glyoxal resins. 
- SEM micrographs showed that the wood-based panels containing an acidic ionic liquid had a smooth and monotonous matrix.

- The particleboard panels prepared with an ionic liquid hardener had higher mechanical strength and better dimensional stability compared to those made from UG resin containing $\mathrm{NH}_{4} \mathrm{Cl}$.

- The gel time of the UG resin was accelerated with increasing [HNMP] $\mathrm{HSO}_{4}$ content.

- MALDI TOF mass spectroscopy indicated that UG resins need to overcome a high energy of activation on curing.

- DSC analysis showed that the addition of IL to the UG resin decrease the energy of activation of the curing reaction to render possible cross-linking.

Author Contributions: Hamed Younesi-Kordkheili contributed the UG resin manufacture, the ionic liquid technology, the DSC and the board making and testing. Antonio Pizzi contributed the UG resin making technology, the ${ }^{13} \mathrm{C}$ NMR and the MALDI TOF analysis and their interpretation

Conflicts of Interest: The authors declare no conflict of interest.

\section{References}

1. Deng, S.; Du, G.; Li, X.; Zhang, J.; Pizzi, A. Performance and reaction mechanism of zero formaldehyde-emission urea-glyoxal (UG) resin. J. Taiwan Inst. Chem. Eng. 2014, 45, 2029-2038. [CrossRef]

2. Deng, S.; Pizzi, A.; Du, G.; Zhang, J.; Zhang, J. Synthesis, structure, and characterization of Glyoxal-Urea-Formaldehyde cocondensed resins. J. Appl. Polym. Sci. 2014, 131, 41009-41019. [CrossRef]

3. Xing, C.; Zhang, S.Y.; Deng, J.; Wang, S. Urea-formaldehyde-resin gel time as affected by the pH value, solid content, and catalyst. J. Appl. Polym. Sci. 2007, 103, 1566-1569. [CrossRef]

4. Sun, Q.N.; Hse, C.Y.; Shupe, C.F. Effect of different catalysts on urea-formaldehyde resin synthesis. J. Appl. Polym. Sci. 2014. [CrossRef]

5. Lu, J.; Yan, F.; Texter, J. Advanced applications of ionic liquids in polymer science. Prog. Polym. Sci. 2009, 34, 431-448. [CrossRef]

6. Deshmukh, K.M.; Qureshi, Z.S.; Patil, Y.P.; Bhanage, B.M. Ionic liquid [NMP]+HSO ${ }_{4}$ : An efficient and recyclable catalyst for the synthesis of 1-Amidoalkyl-2-naphthols and 1-carbamatoalkyl-2-naphthols under solvent free conditions. Synthetic Commun. 2012, 42, 93-101. [CrossRef]

7. Wang, X.; Han, M.; Wan, H.; Yang, C.; Guan, G. Study on extraction of thiophene from model gasoline with Brønsted acidic ionic liquids. Fron. Chem. Sci. Eng. 2011, 5, 107-112. [CrossRef]

8. Pizzi, A.; Vosloo, R.; Cameron, A.; Orovan, E. Self- neutralizing acid-set PF wood adhesives. Holz. Roh. Werkst. 1986, 44, 229-234. [CrossRef]

9. Younesi-Kordkheili, H.; Kazemi Najafi, S.; Behrooz, R.; Pizzi, A. Improving urea formaldehyde resin properties by glyoxalated soda bagasse lignin. Holz. Roh. Werkst. 2015, 73, 77-85. [CrossRef]

10. Younesi-Kordkheili, H.; Pizzi, A.; Niyatzade, G. Reduction of formaldehyde emission from particleboard by phenolated kraft lignin. J. Adhes. 2015. [CrossRef]

11. Younesi-Kordkheili, H.; Kazemi-Najafi, S.; Behrooz, R. Influence of nanoclay on urea-glyoxalated lignin-formaldehyde resins for wood adhesive. J. Adhes. 2015. [CrossRef]

12. European Committee for Standardization. European Norm EN 319: 1993 Perpendicular Tensile Strength on Particleboards and Fibreboards; European Committee for Standardization: Brussels, Belgium, 1993.

13. European Committee for Standardization. European Norm EN 310: 1993 Wood-Based Panels-Determination of Modulus of Elasticity in Bending and of Bending Strength; European Committee for Standardization: Brussels, Belgium, 1993.

14. ASTM. ASTM D 4442: 2007 Standard Test Methods for Direct Moisture Content Measurement of Wood and Wood-Base Materials; ASTM: West Conshohocken, PA, USA, 2007.

15. Mao, A.; Hassan, E.B.; Kim, M.G. Investigation of low mole ratio UF and UMF resins aimed at lowering the formaldehyde emission potential of wood composite boards. Bioresources 2013, 8, 2453-2469. [CrossRef]

16. Xing, C.; Zhang, S.Y.; Deng, J. Effect of wood acidity and catalyst on UF resin gel time. Holzforschung 2005, 58, 408-412. [CrossRef] 
17. Gao, Z.; Wang, X.M.; Wan, H.; Liu, Y. Curing characteristics of urea-Formaldehyde resin in the presence of various amounts of wood extracts and catalysts. J. Appl. Polym. Sci. 2008, 107, 1555-1562. [CrossRef]

18. Paiva, N.T.; Henriques, A.; Cruz, P.; Ferra, J.M.; Carvalho, L.H.; Magalhaes, F.D. Production of melamine fortified urea-formaldehyde resins with low formaldehyde emission. J. Appl. Polym. Sci. 2012, 124, 2311-2317. [CrossRef]

19. Kardos, J.L.; Dudu, K.; Dave, R. Void growth and resin transport during processing of thermosetting-Matrix composites. Adv. Polym. Sci. 1986, 80, 101-123.

20. Hse, C.Y.; Xia, Z.Y.; Tomita, B. Effects of reaction $\mathrm{pH}$ on properties and performance of urea-formaldehyde resins. Holzforchung 1994, 48, 527-532. [CrossRef]

21. Taghyari, H.R.; Rangavar, H.; Bibalan, O.F. Effect of nanosilver on reduction of hot pressing time and improvement in physical and mechanical properties of particleboard. Bioresources 2011, 6, 4067-4075.

(C) 2016 by the authors; licensee MDPI, Basel, Switzerland. This article is an open access article distributed under the terms and conditions of the Creative Commons by Attribution (CC-BY) license (http://creativecommons.org/licenses/by/4.0/). 